\title{
Evidence for Taxonomic Utility of Periodic Acid- Thiocarbohydrazide-Silver Proteinate Cytochemical Staining for Electron Microscopy
}

\author{
NALIN RASTOGI, ${ }^{*}$ CLAUDE FREHEL, ${ }^{2}$ AND HUGO L. DAVID ${ }^{1}$ \\ Service de la Tuberculose et des Mycobactéries, ${ }^{1}$ and Unité de Microscopie Electronique, Département de Biologie \\ Moléculaire, ${ }^{2}$ Institut Pasteur, 75015 Paris, France
}

\begin{abstract}
Various species of bacteria belonging to taxonomically separate genera were studied by using electron microscopy and different cytochemical staining methods. Judging from our results and those reported previously in the literature, we concluded that the periodic acid-thiocarbohydrazide-silver proteinate reaction (Thiéry method) separates the bacteria into four large groups according to the production of silver grains at the site of the cell wall or the cytoplasmic membrane or both. In the CorynebacteriumMycobacterium-Nocardia group only the cytoplasmic membrane reacts; in Bacillus and Bricella only the cell wall reacts; in Lactobacillus and Microbacterium both the cell wall and the cytoplasmic membrane react; and in Escherichia and Clostridium neither the cell wall nor the cytoplasmic membrane reacts. Moreover, this staining method clearly separated Mycobacterium leprae from certain leprosy-derived coryneform bacteria.
\end{abstract}

Both the Gram and the Ziehl-Neelsen staining procedures used in visible light microscopy separate bacteria into two major goups. In this paper we propose that the periodic acidthiocarbohydrazide-silver proteinate staining method of Thiéry for electron microscopy (17) may also be useful for taxonomic purposes. Other electron microscopic cytochemical methods (acidic phosphotungstic [PTA] and ruthenium red [RR] staining methods) do not appear to have discriminative value.

\section{MATERIALS AND METHODS}

Organisms and growth. Mycobacterium avium ATCC 15769, Mycobacterium aurum CIPT 141210005, Mycobacterium smegmatis ATCC 607, Mycobacterium tuberculosis $\mathrm{H}_{37} \mathrm{Ra}$, Mycobacterium leprae, Corynebacterium pseudotuberculosis CIP 5297, Microbacterium flavum CIP 695 (-ATCC 10340), Lactobacillus acidophilus CIP 6218 (-ATCC 9857), Nocardia asteroides CIP 721, and three strains of leprosy-derived corynebacteria (strains Kim, FPSA, and 43LL; kindly supplied by L. Barksdale, Department of Microbiology. New York University Medical Center) were used in this investigation.

All of the above organisms except Mycobacterium leprae were grown in liquid medium; Mycobacterium leprae was isolated and purified from the liver tissues of an experimentally infected armadillo designated WR-45 (kindly supplied through the World Health Organization-IMMLEP Bank, National Institute of Medical Research, London, England). Our results were also verified with Mycobacterium leprae isolated from the liver tissues of armadillo AU (Mycobacterium leprae Bank, Institut Pasteur, Paris, France). The procedure used for harvesting Mycobacterium leprae has been described previously (1).

Most of the above organisms (but not Mycobacterium leprae) were grown in $\mathrm{RVB}_{10}$ liquid medium (13) at $37^{\circ} \mathrm{C}$; Microbacterium flavum and $N$. asteroides were grown in $\mathrm{RVB}_{10}$ medium at $30^{\circ} \mathrm{C}$, and $L$. acidophilus was grown in

\footnotetext{
* Corresponding author.
}

MRS liquid medium (7) at $37^{\circ} \mathrm{C}$. $\mathrm{RVB}_{10}$ liquid medium was prepared as described previously (13), and MRS liquid medium was purchased from Institut Pasteur Production, Paris, France.

Mycobacterium avium was used only in its smooth, transparent $(\mathrm{SmT})$ colony variant form, which was obtained as described previously (11).

Ultrastructural studies. The methods used for fixation, dehydration, embedding, and ultratomy have been described previously (10-12). Thin sections were examined with a Siemens model 101 electron microscope after lead citrate staining, as well as after other cytochemical staining procedures which were performed as described below. (i) The Thiéry method (17) was used to localize the polysaccharides containing $\alpha-1-2$ glycol bonds which were oxidized by periodic acid to give aldehydes, which in turn were detected by thiocarbohydrazide; the thio radicals were made visible by silver grain precipitates. The original method of Thiéry (17) was performed with slight modifications, as described previously $(10-12)$. To be sure that there was no possible interference due to free aldehyde groups, in parallel control experiments the method described above was used without prior treatment with periodic acid so as to prevent the opening of $\alpha-1-2$ glycol bonds. There were no silver grain precipitates in control experiments, however, and this excluded the possibility of any aldehyde contamination in our test preparations.

(ii) PTA staining has been shown to stain the peptidoglycan of bacterial walls (15), and this staining method was performed as described previously $(10,11)$, using the original method of Rambourg (9).

(iii) The RR stain does not penetrate intact bacteria and therefore, is used to locate outer polysaccharides of bacteria. This reaction (6) was performed as applied previously to mycobacteria $(10,11)$.

Thiéry staining was also performed on plasmolyzed bacteria to ascertain the localization of silver grains on the cell wall or cytoplasmic membrane or both. In this case, the bacteria were plasmolyzed for $1 \mathrm{~h}$ at $37^{\circ} \mathrm{C}$ in $100 \mathrm{mM}$ Michaelis-Veronal buffer ( $\mathrm{pH}$ 6.8) containing $1 \mathrm{M}$ sucrose and then fixed for electron microscopy as usual. 

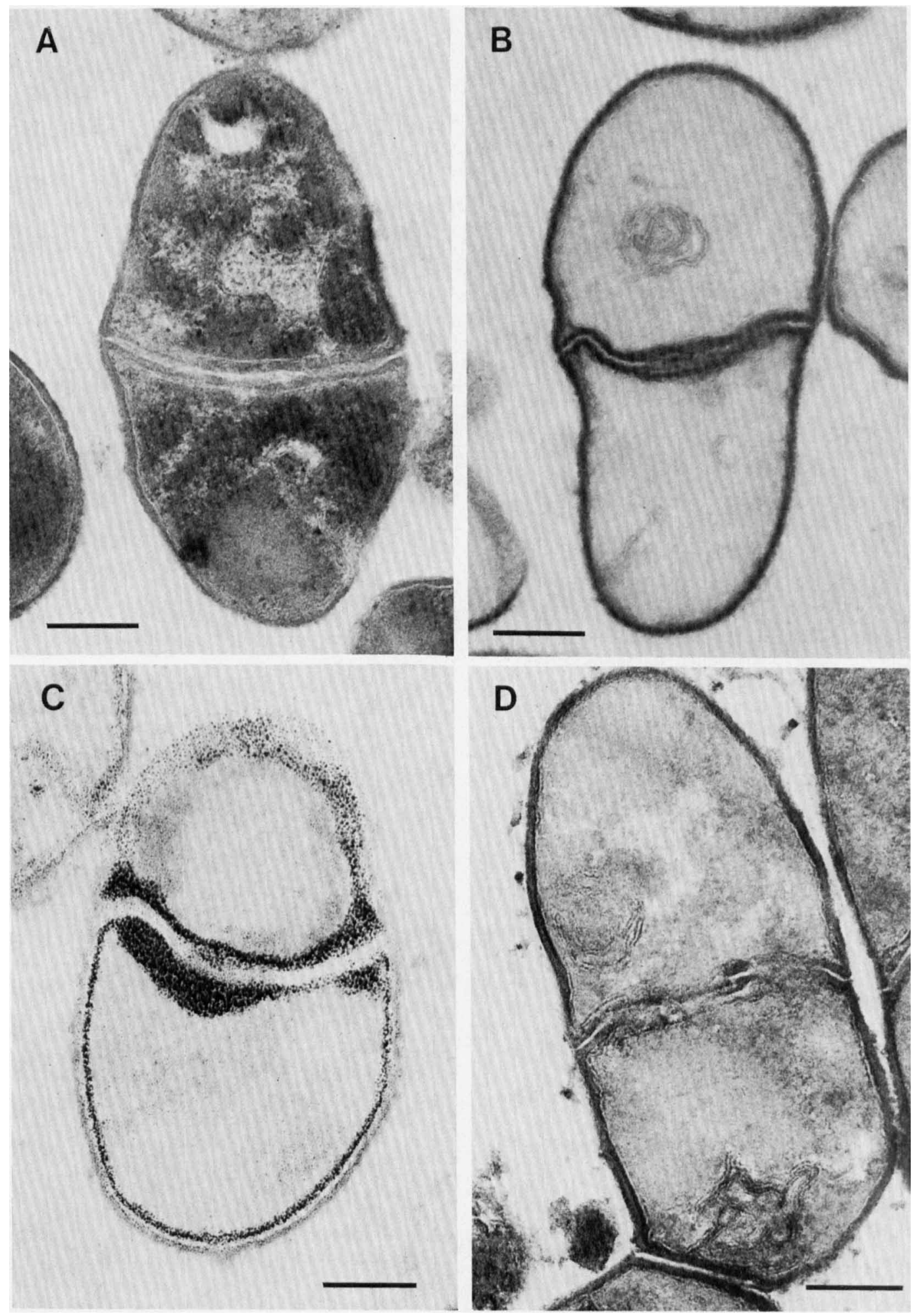

FIG. 1. Ultrastructure of Corynebacterium pseudotuberculosis after lead citrate (A), PTA (B), Thiéry (C), and RR (D) staining. Bar $=200$ $\mathrm{nm}$.

\section{RESULTS AND DISCUSSIONS}

Figures 1 through 4 show the typical staining properties of different organisms after the lead citrate, PTA, Thiéry, and RR staining methods were used. Figure 5 is a summary of the cytochemical staining profiles of the different organisms studied during this investigation.

PTA has been shown to stain preferentially the peptidoglycan layer of different gram-positive bacteria (15) and mycobacteria $(10,11)$. We found (Fig. 1B, 2B, 3C, 3H, 4B, and 5) 

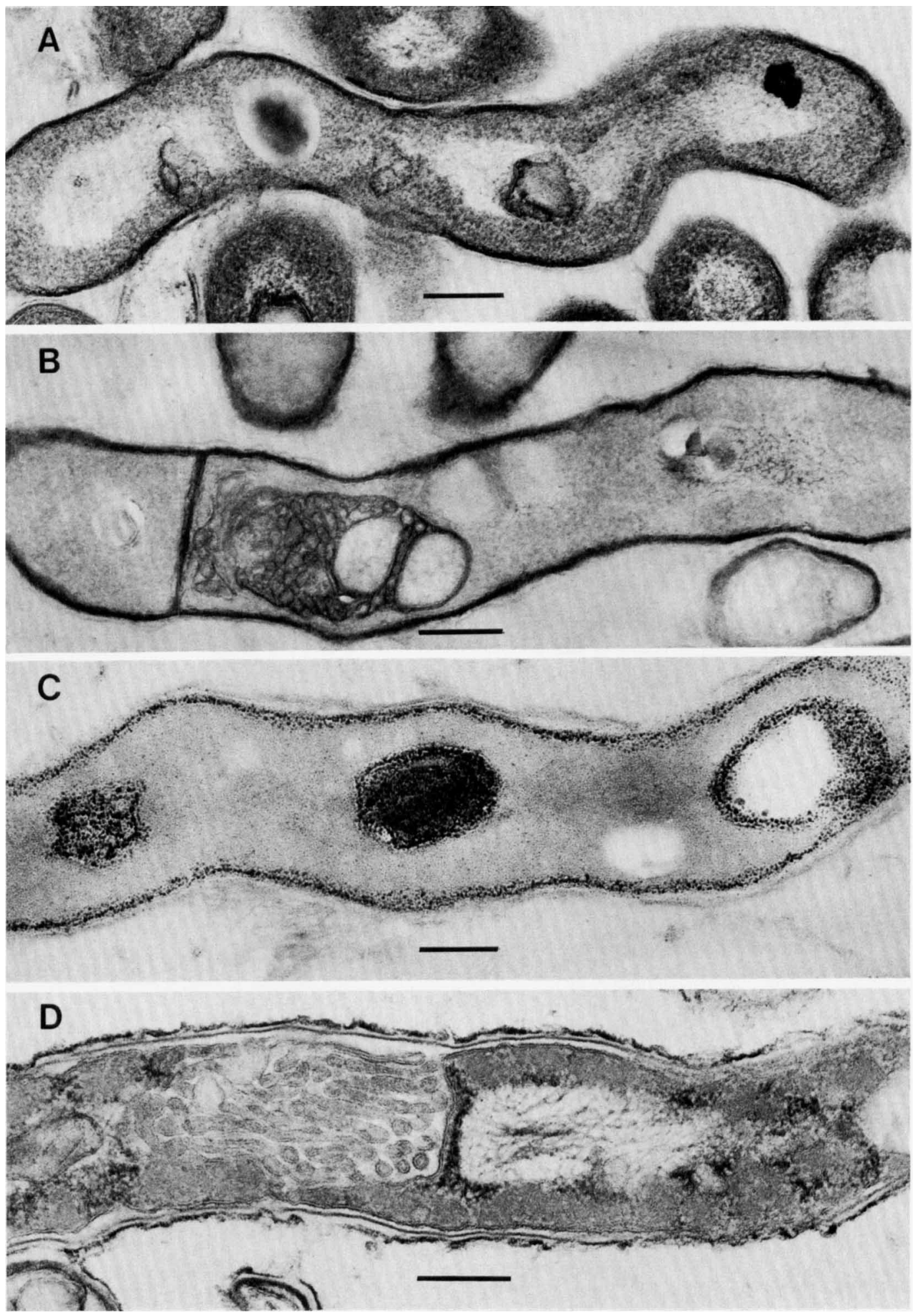

FIG. 2. Ultrastructure of $N$. asteroides after lead citrate (A), PTA (B), Thiéry (C), and RR (D) staining. Bar $=200 \mathrm{~nm}$.

that PTA always stained wall peptidoglycan and the outer layer of the cytoplasmic membrane in all of the genera and species which we studied; consequently, this staining method had no discriminative taxonomic value.

RR staining has been used previously to reveal polysac- charide outer layers in Mycobacterium avium and Mycobacteritum leprae $(10,11)$. During this investigation, $\mathrm{RR}$ staining revealed polysaccharide outer layers in these two mycobacteria, in Mycobacterium aurum, and in N. asteroides and revealed polysaccharide exopolymers in leprosy-derived co- 

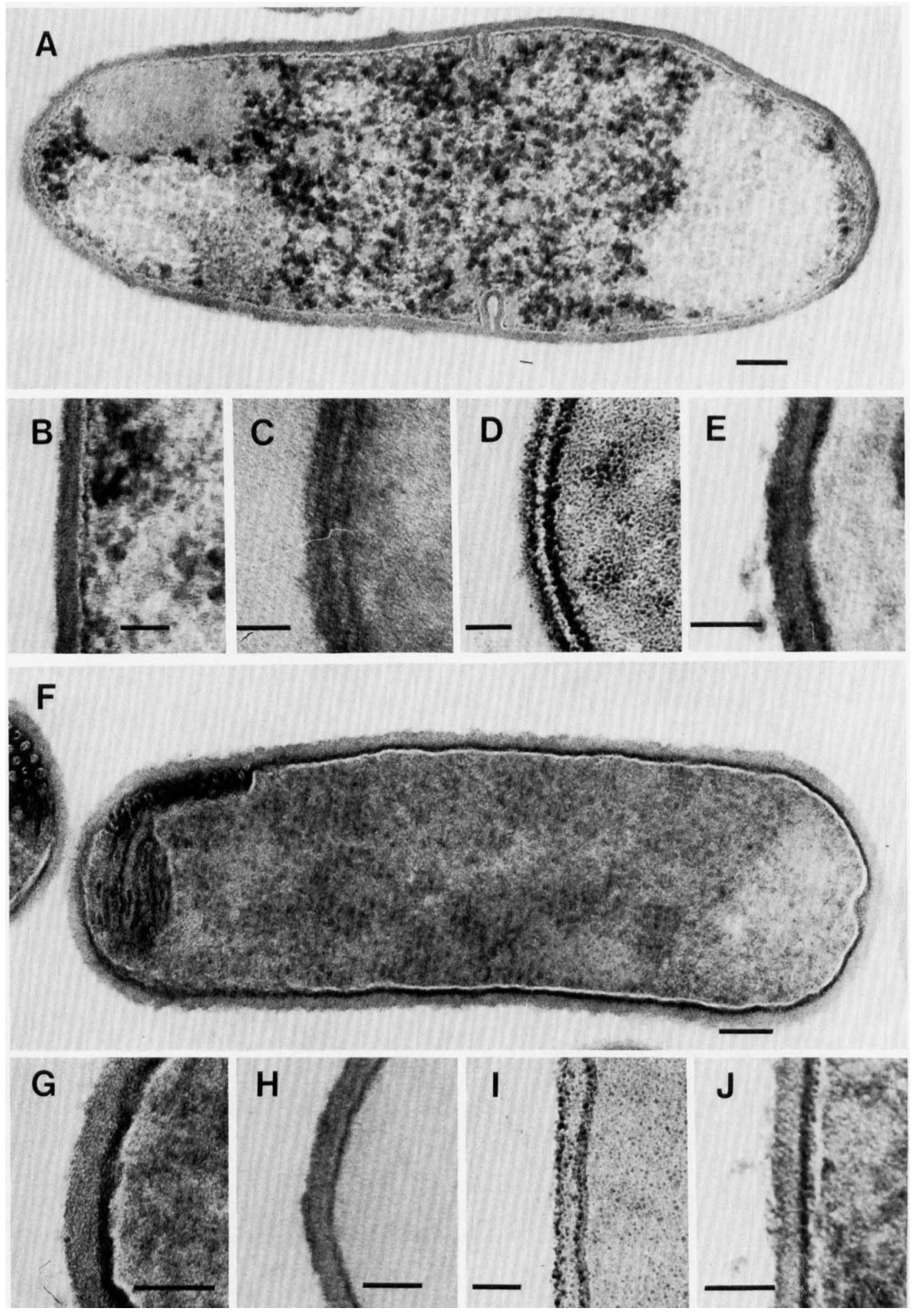

FIG. 3. Electron micrographs of Microbacterium flavum and L. acidophilus. (A through E) Ultrastructure of Microbacterium flavim after lead citrate (A and B), PTA (C), Thiéry (D), and RR (E) staining (A) Bar $=100 \mathrm{~nm}$. (B through E) Bar $=50 \mathrm{~nm}$. (F through J) Ultrastructure of L. acidophilus after lead citrate (F and $\mathrm{G})$, PTA $(\mathrm{H})$, Thiéry (I), and RR (J) staining. (F) Bar $=100 \mathrm{~nm}$. (G through J) Bar $=50 \mathrm{~nm}$.

rynebacterial strain Kim (Fig. 4D and 5). However, it did not reveal polysaccharide outer layers when Mycobacterium avium was grown to give the smooth, opaque, dome-shaped (SmD) colony type (11). This suggested that the RR staining profile was affected by the culture conditions of the bacteria and therefore had no discriminative value.

The Thiéry staining procedure, on the other hand, revealed that each microorganism reacted differently (Fig. 1 

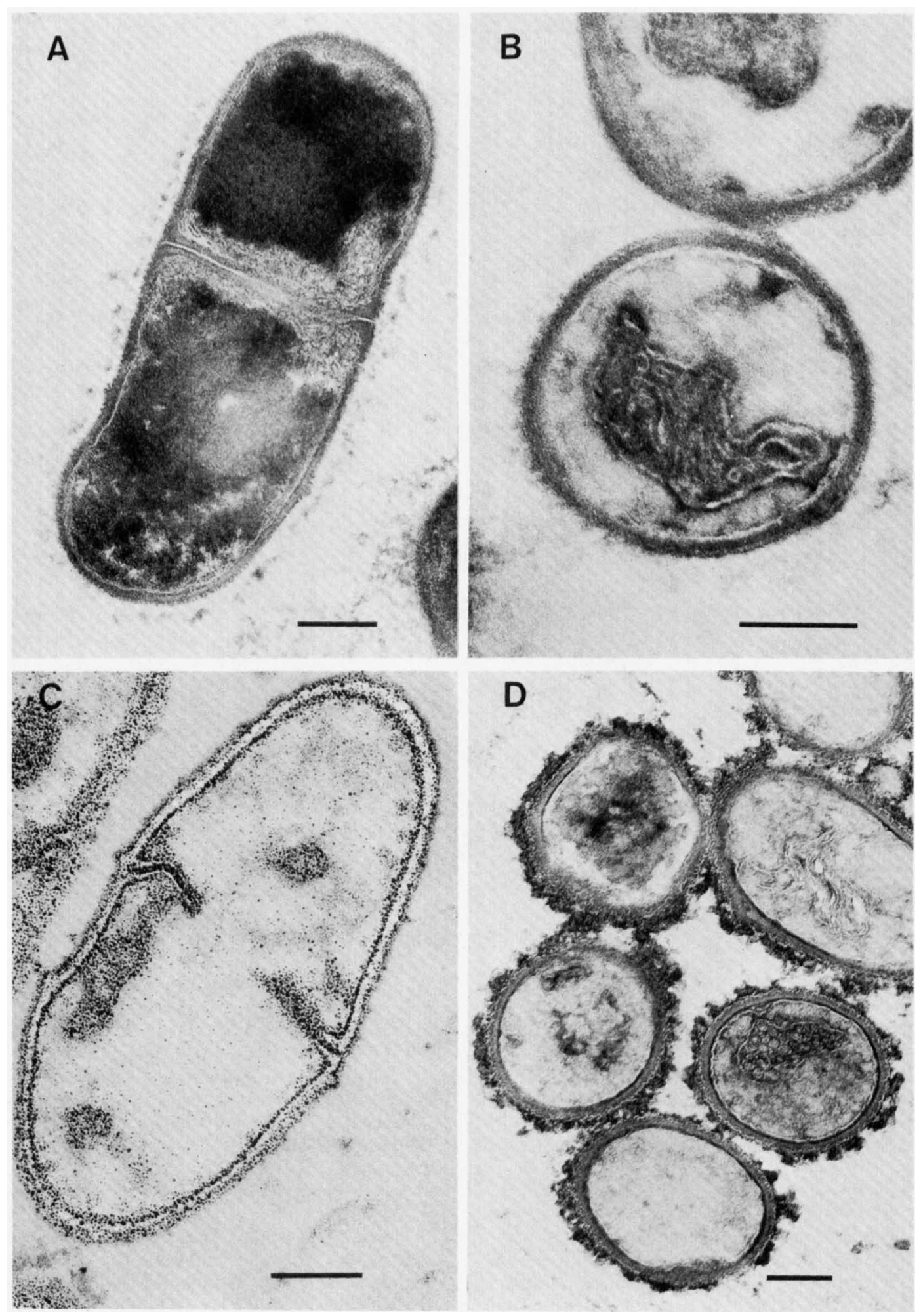

FIG. 4. Ultrastructure of leprosy-derived corynebacterial strain Kim after lead citrate (A). PTA (B), Thiéry (C), and RR (D) staining. Bar $=200 \mathrm{~nm}$.

through 5 and Table 1). The Thiéry-stained profile of each microorganism was stable and reproducible despite different culture conditions (e.g., Mycobacterium avium grown in vitro and in vivo or Mycobacterium avium SmD and SmT colony types maintained similar staining profiles $(10,11$; this study).

For the reasons given above, we have summarized the results obtained in this investigation and those reported 

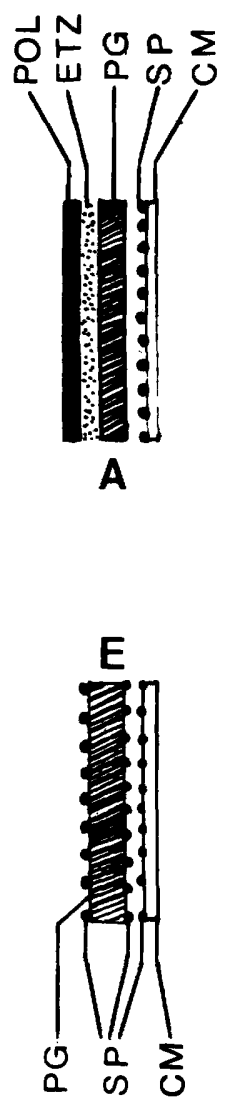

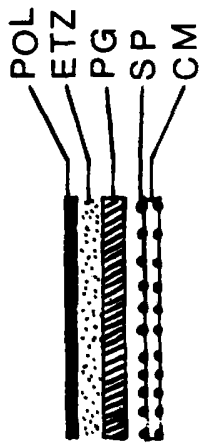

B

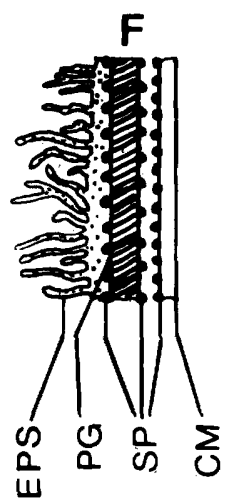

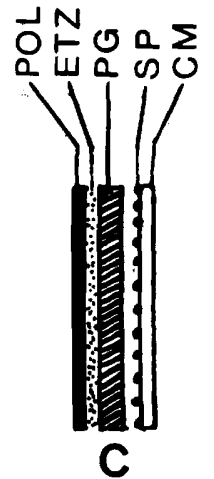
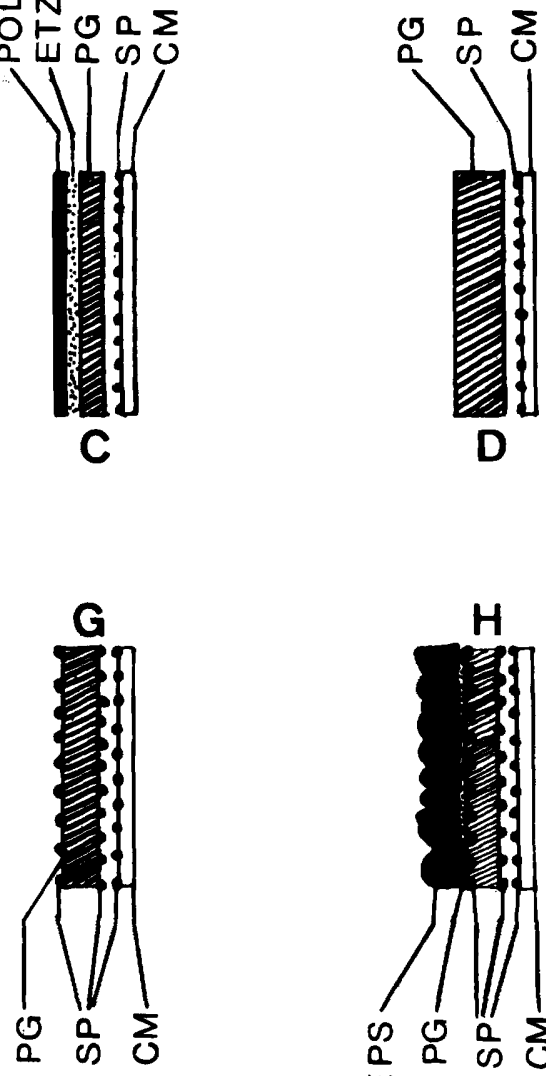

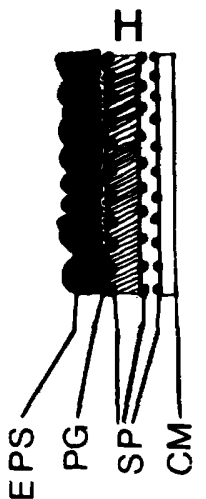

FIG. 5. Diagrammatic representation of the cell envelopes from Mycobacterium avium SmT (A), Mycobacterium leprae (B), $N$. asteroides (C), Corynebacterium pseudotuberculosis (D), Microbacterium fiavum and L. acidophilus (E), and leprosy-derived corynebacterial strains FPSA (F), 43LL (G), and Kim (H). (For other details see text and Table 1.) Abbreviations: CM, cytoplasmic membrane: PG, peptidoglycan: SP, location of silver grain precipitation after Thiéry staining; ETZ, electron-transparent zone of the cell wall; POL, polysaccharide outer layer revealed by RR staining; EPS, exopolymers (only the exopolymers from strain Kim are polysaccharides and consequently are revealed by RR staining). The dots represent the silver grain deposits after Thiéry staining. Note that in Mycobacterium leprae both layers of the cytoplasmic membrane were stained with this method.

previousty in the literature in Table 1 , which shows that Thiéry staining separates the bacteria into the following four large groups: (i) organisms in which the cytoplasmic membranes but not the cell walls are Thiéry positive (e.g.. members of the Corynebacterium-Mycobacterium-Nocardia group which we studied); (ii) organisms in which the cell walls but not the cell membranes are Thiéry positive (e.g., Bacillus cereus, Bacillus subtilis, Bacillus megaterium, Brucella abortus, and Brucella melitensis); (iii) organisms in which both the cell walls and the cell membranes are Thiéry positive (e.g., L. acidophilus, Microbacterium flavum, and the three strains of leprosy-derived corynebacteria which we studied); and (iv) organisms in which neither the cell walls nor the cell membranes are Thiéry positive (e.g., Escherichia coli and Clostridium butyricum).

Although we emphasize Thiéry staining of the cell walls or the cell membranes or both for discriminative purposes, it is possible that finer examination of stained cells may provide additional information. For example, in Microbacterium flavum (Fig. 3D) and L. acidophilus (Fig. 3I), only the outer surface of the cell wall material was stained, resulting in only one silver precipitation line corresponding to the cell walls. Plasmolyzed cells confirmed that the second, inner silver precipitation line observed corresponded to the cell mem- branes. On the other hand, the two silver precipitation lines observed previously in Bacillus subtilis and Bacillus megaterium corresponded to the site of the cell wall material ( 3 , 4). Similarly, in the case of $E$. coli neither the cell walls nor the cell membranes were stained after the Thiéry reaction; however, the polysaccharide slime covering the outer membranous layer of the cell walls was stained with this method (8). In Brucella abortus and Brucella melitensis, both the cell walls and the polysaccharide slime were stained (2). To what extent this finer examination of the Thiéry coloration profile may be useful for taxonomic purposes is still not known.

The bacteria contain many substances that are capable of reacting with periodic acid; however, these substances must be so arranged in the architecture of the intact cells that they are not accessible to Thiéry staining. Judging from our own studies and those described previously (Table 1), the substances that react during Thiéry staining appear to be distributed in a characteristic fashion for each organism. Thus, even though the exact nature of the substance(s) might not be known, the regularity of the staining reaction shows the usefulness of the Thiéry staining method for taxonomic purposes. While searching for methods to characterize $M y$ cobacterium leprae, we verified that the cell membrane but not the cell wall of this organism was stained by the Thiéry 
TABLE 1. Cytoplasmic membrane and wall structures stained by the Thiéry method in different microorganisms

\begin{tabular}{|c|c|c|c|}
\hline \multirow[b]{2}{*}{ Organism } & \multicolumn{2}{|c|}{$\begin{array}{l}\text { Location of silver } \\
\text { grains }\end{array}$} & \multirow[b]{2}{*}{ Reference(s) } \\
\hline & $\begin{array}{l}\text { Cytoplas- } \\
\text { mic mem- } \\
\text { brane }\end{array}$ & $\begin{array}{l}\text { Cell } \\
\text { wall }\end{array}$ & \\
\hline $\begin{array}{l}\text { Corynebacterium pseu- } \\
\text { dotuberculosis }\end{array}$ & + & - & This study \\
\hline Mycobacterium avium & + & - & 10,11 ; this study \\
\hline Mycobacterium aurum & + & - & This study \\
\hline $\begin{array}{l}\text { Mycobacterium smegma- } \\
\text { tis }\end{array}$ & + & - & 12, this study \\
\hline $\begin{array}{l}\text { Mycobacterium tubercu- } \\
\text { losis } \mathrm{H}_{37} \mathrm{Ra}\end{array}$ & + & - & This study \\
\hline Mycobacterium phlei & + & - & 8 \\
\hline Mycobacterium leprae & + & - & 10,16 ; this study \\
\hline Nocardia asteroides & + & -. & This study \\
\hline Nocardia corallina & + & - & 14 \\
\hline Bacillus megaterium & - & + & 3,4 \\
\hline Bacillus subtilis & - & + & $3,4,15$ \\
\hline Bacillus cereus & - & + & 8 \\
\hline Brucella abortus $^{b}$ & - & + & 2 \\
\hline Brucella melitensis ${ }^{b}$ & - & + & 2 \\
\hline Microbacterium flavum & + & + & This study \\
\hline Lactobacillus acidophilus & + & + & This study \\
\hline LDC strain FPSA ${ }^{c}$ & + & + & This study \\
\hline LDC strain 43LL' & + & + & This study \\
\hline LDC strain Kim ${ }^{c}$ & + & + & This study \\
\hline Escherichia colid & - & - & 8 \\
\hline Clostridium butyricum & - & - & 15 \\
\hline
\end{tabular}

"Unlike all other microorganisms, in Mycobacterium leprae both layers of the cytoplasmic membrane were stained by the Thiéry method.

${ }^{b}$ Although the cytoplasmic membranes were often Thiéry negative, it has been reported that rarely they can be weakly positive.

"LDC. Leprosy-derived corynebacterium.

${ }^{d}$ Although the cell walls were Thiéry negative, the polysaccharide slime covering the outer membranous layer of the cell wall was Thiéry positive.

method (10), which agreed well with previous observations with Mycobacterium phlei (8). Our observations on the characteristic staining of the mycobacteria (10-12) have been confirmed (16), and, as shown above (Fig. 5 and Table 1), the Thiéry staining method clearly separates Mycobacterium leprae from certain coryneforms, which are considered by some investigators to be the cultivable forms of the leprosy bacilli (5).

In conclusion, it appears that further investigations on a broad range of bacteria should confirm that the periodic acid-thiocarbohydrazide-silver proteinate reaction (Thiéry method) may be a useful differential taxonomic criterion for characterizing bacteria.

\section{LITERATURE CITED}

1. David, H. L., F. Clément, and L. Meyer. 1978. Adsorption of mycobacteriophage $\mathrm{D}_{29}$ on Mycobacterium leprae. Ann. Microbiol. (Paris) 129A:563-566.

2. Dubray, G. 1975. Influence de la fixation sur la mise en évidence cytochimique des polysaccharides des bactéries du genre Br:Icella. J. Microsc. (Paris) 24:59-74.

3. Frehel, C., P. Robbe, R. Tinelli, and A. Ryter. 1982. Relationship between biochemical and cytochemical results obtained on Bacillus megaterium and Bacillus subtilis cell-wall polysaccharides. J. Ultrastruct. Res. 81:78-87.

4. Frehel, C., and A. Ryter. 1982. Electron microscopic cytochemical study of cell-wall polysaccharides of Bacillus subtilis and two strains of Bacillus megaterium. J. Ultrastruct. Res. 81:6677.

5. Imaeda, T., W. F. Kirchheimer, and L. Barksdale. 1982. DNA isolated from Mycobacterium leprae: genome size, base ratio, and homology with other related bacteria as determined by optical DNA-DNA reassociation. J. Bacteriol. 150:414-417.

6. Luft, J. H. 1971. Ruthenium red and violet. I. Chemistry. purification, methods of use for electron microscopy and mechanism of action. Anat. Rec. 171:347-368.

7. Man, J. C., M. Rogosa, and M. E. Sharpe. 1960. A medium for the cultivation of lactobacilli. J. Appl. Bacteriol. 23:130-135.

8. Petitprez, A., and J. C. Derieux. 1970. Mise en évidence de polysaccharides sur quelques types de bactéries. J. Microsc. (Paris) 9:263-272.

9. Rambourg, A. 1967. Détection des glycoprotéines en microscopie électronique: coloration de la surface cellulaire et de l'appareil de golgi par un mélange acide chromique-phosphotungstique. C. R. Acad. Sci. 265:1426-1428.

10. Rastogi, N., C. Frehel, A. Ryter, and H. L. David. 1982. Comparative ultrastructure of Mycobacterium leprae and $M$. avium grown in experimental hosts. Ann. Microbiol. (Paris) 133B:109-128.

11. Rastogi, N., C. Frehel, A. Ryter, H. Ohayon, M. Lesourd, and H. L. David. 1981. Multiple drug resistance of Mycobacterium avium: is the wall architecture responsible for the exclusion of antimicrobial agents? Antimicrob. Agents Chemother. 20:666677.

12. Rastogi, N., J. Moniz-Pereira, C. Frehel, and H. L. David. 1983. Ultrastructural evidence for the accumulation of a polysaccharide-like substance during mycobacteriophage $\mathrm{D}_{29}$ replication in Mycobacterium smegmatis. Ann. Virol. (Inst. Pasteur) 134E:251-266.

13. Redmond, W. B., and D. M. Ward. 1966. Media and methods for phage-typing mycobacteria. Bull. W.H.O. 35:563-568.

14. Robertson, J. G., P. Lyttleton, K. I. Williamson, and R. D. Batt. 1975. The effect of fixation procedures on the electron density of polysaccharide granules in Norcardia corallina. J. Ultrastruct. Res. 50:321-332.

15. Rousseau, M., and J. Hermier. 1975. Localisation en microscopie électronique des polysaccharides de la paroi chez les bactéries en sporulation. J. Microsc. Biol. Cell. (Paris) 23:237-248.

16. Silva, M. T., and P. M. Macedo. 1983. A comparative ultrastructural study of the membranes of Mycobacterium leprae and cultivable mycobacteria. Biol. Cell. (Paris) 47:383-386.

17. Thiéry, J. P. 1967. Mise en évidence des polysaccharides sur coupes fines en microscopie électronique. J. Microsc. (Paris) 6:987-1018. 